\title{
A UTILIZAÇÃO DO INSTAGRAM POR ATLETAS OLÍMPICOS BRASILEIROS: PERFIL TRAÇADO POR UMA ANÁLISE DE IMAGENS
}

\author{
The Instagram use by brazilian olympic athletes: profile outlined by image \\ analysis \\ El uso de Instagram por atletas olímpicos brasileños: perfil esbozado por una \\ análisis de imagenes.
}

Vivian de Oliveira

Docente no Centro Universitário FIEO (UNIFIEO) - Osasco, Brasil vivian_oliveira58@hotmail.com

André Luis Aroni

Docente no Centro Universitário UniMetrocamp Wyden - Campinas, Brasil andre-aroni@hotmail.com

Luciana Botelho Ribeiro Doutoranda em Desenvolvimento Humano e Tecnologias (UNESP) - Rio Claro, Brasil lulu_bribeiro@hotmail.com

Kauan Galvão Morão Doutorando em Desenvolvimento Humano e Tecnologias (UNESP) - Rio Claro, Brasil kauangm@hotmail.com Afonso Antonio Machado Docente na Universidade Estadual Paulista (UNESP) - Rio Claro, Brasil afonsoa@gmail.com

\section{Resumo}

O objetivo do estudo foi verificar o conteúdo das fotos postadas no Instagram por atletas olímpicos brasileiros. Foram analisadas por um período de quatro meses as fotos postadas pelos atletas que foram medalhistas nos Jogos Olímpicos de Londres, baseando-se nos pressupostos da Sociologia Visual. Como principais resultados, encontramos que há uma relação entre o número de postagens e o total de seguidores. Verificamos também que o maior número de fotos postadas é dos próprios atletas, em ambientes de trabalho e em momentos de descontração. Na maioria das fotos não há referência aos patrocinadores dos atletas, destaque ao corpo ou a vestimenta dos mesmos.

Palavras-chave: Redes Sociais. Atletas Olímpicos. Tecnologias. 


\begin{abstract}
The objective of the study was to verify the content of the photos posted on Instagram by Brazilian Olympians. Were analyzed for a period of four months the photos posted by athletes who won medals at the London Olympic Games, based on the assumptions of Visual Sociology. As main results, we find that there is a relationship between the number of posts and the total of followers. We also found that the largest number of photos posted is of the athletes themselves, in work environments and moments of relaxation. In the most of the photos there is no reference to the sponsors of the athletes, highlight the body or clothing of the same.
\end{abstract}

Key words: Social Networks. Olympians. Technologies.

\title{
Resumen
}

El objetivo del estudio fue verificar el contenido de las fotos publicadas en Instagram por olímpicos brasileños. Fueran analizadas por un período de cuatro meses las fotos publicadas por los atletas que fueron medallistas en los Juegos Olímpicos de Londres, con base a los supuestos de la Sociología Visual. Como principales resultados, encontramos que existe una relación entre el número de publicaciones y el total de seguidores. También se encontró que el mayor número de fotos que aparece son de los atletas mismos, en los ambientes de trabajo y momentos de relajación. La mayoría de las fotos no se hace referencia a los patrocinadores de los atletas, resalte el cuerpo o la ropa de ellos.

Palabras clave: Redes Sociales. Atletas Olímpicos. Tecnologías.

\section{INTRODUÇÃO}

Na visão de Azambuja (2012, p. 89), “as subjetividades de cada época se apropriam das tecnologias e produzem nesse processo novos modos de viver, maneiras inéditas de sentir e ver o mundo". Para ele, algumas tecnologias condicionam a vida social e trazem novas possibilidades. Um ótimo exemplo deste tipo de tecnologia é a Internet.

Vivemos em uma era cada vez mais conectada. A cibercultura é definida por Lemos (2010) como o produto da associação entre a cultura contemporânea e as novas tecnologias, quando estas criam um novo vínculo entre a técnica e a vida social. Segundo Kozinets (2014), talvez hoje não tenha mais sentido falarmos sobre cibercultura como distinta de outras formas de cultura humana.

De acordo com Keen (2012) a Internet é, atualmente, onde vivemos. Deste modo, ela torna-se um reflexo tanto de nós mesmos enquanto seres humanos, quanto dos valores dominantes da sociedade. Kozinets (2014) nos diz que cada vez mais os cientistas sociais concluem que não é possível compreender totalmente muitas das particularidades da vida 
social e cultural sem incorporar em seus estudos a Internet e as comunicações mediadas por computador e/ou outros dispositivos eletrônicos.

Dentro do universo da Internet, estão as redes sociais, que são uma realidade já consolidada. Para Piza (2012, p. 20), "as redes sociais na Internet se apresentam como uma rede de atores formada pela interação social que é mediada por um dispositivo técnico com acesso à Internet”. Segundo a autora, as redes sociais permitem a criação de novos grupos sociais, chamados comunidades virtuais, que são novas formas de inserções coletivas no ciberespaço (PIZA, 2012). Para McLuhan (2005 apud SILVA, 2012), a presença das mídias configura um outro modo de existir socialmente.

As questões que envolvem a Internet e seus domínios são bastante complexas e variadas. Não podemos considerar as redes sociais e outras ferramentas do mundo ciber como boas, más, muito menos como neutras (LÉVY, 1999; AZAMBUJA, 2012). Como uma das questões principais da vida em rede, está a relação entre privacidade e exposição. Segundo Keen (2012) o desejo de privacidade, que era considerado a norma cultural dominante na era industrial, não se concretiza nos dias atuais.

Quando falamos das nossas ações e práticas dentro do ambiente da Internet, costumamos usar o termo "virtual". Isso porque, em geral, acreditamos que uma coisa deva ser ou real ou virtual, que ela não pode, portanto, possuir os dois estados ao mesmo tempo. Contudo, segundo Lévy (1999), em filosofia o virtual não se opõe ao real. O autor conclui que, na verdade, o virtual é real.

Diante disso, é necessária a consciência de que toda ação é seguida de uma reação. O uso das ferramentas das redes sociais deve ser cuidadoso, pois pode trazer consequências para os seus usuários, e que em muitas vezes não são positivas. Quando falamos em pessoas famosas, falamos sobre um enorme número de seguidores, e por esse motivo, suas publicações alcançam uma maior quantidade de indivíduos, fazendo com que os seus efeitos sejam potencializados.

No esporte, isto não é diferente. Cada vez mais os atletas alcançam status de celebridade, e as redes sociais para eles seguem essa mesma lógica. Não é difícil encontrarmos na Internet sites que ranqueiam os melhores atletas para serem seguidos no Twitter, no Instagram e em outras redes sociais. As pessoas acompanham o que é postado pelos esportistas. As novas mídias sociais permitem com que as pessoas se tornem cada vez mais os próprios narradores de suas vidas e suas histórias (AZAMBUJA, 2012). Silva (2012) concorda ao dizer que no mundo contemporâneo em que vivemos, os receptores tornam-se 
produtores de seus próprios conteúdos, não só por meio de textos e imagens que compartilham, mas também pela possibilidade de escolhas a serem feitas, como por exemplo, quem pode ver minhas publicações, quais informações eu quero que cheguem até mim, etc.

Quando falamos no Instagram especificamente, falamos de uma rede social cujo foco é a imagem. É atualmente a segunda maior rede social em número de usuários, e parece ser também bastante popular entre os atletas. Além disso, os atletas não estão blindados contra as polêmicas relacionadas ao uso das redes sociais. Alguns esportistas que utilizam o Instagram, como o jogador de futebol brasileiro Hulk e o atleta inglês Leroy Fer envolveram-se em incidentes relacionados com racismo e nudez.

Diante disso, nos perguntamos: o que os atletas costumam publicar em seus perfis no Instagram? Como eles utilizam esta rede social? São questões como essas procuramos responder ao longo dessa pesquisa. Portanto, o objetivo do presente estudo foi identificar o conteúdo das fotos postadas no Instagram por atletas brasileiros medalhistas nos Jogos Olímpicos de Londres, em 2012. Para isso, analisamos imagens publicadas nas redes sociais de 40 atletas olímpicos brasileiros (28 do sexo masculino e 12 do sexo feminino), de modalidades coletivas e individuais, com base nos pressupostos da Sociologia Visual. A coleta de dados foi feita em um período de 121 dias, totalizando 2.025 imagens analisadas.

\section{REVISÃO DE LITERATURA}

O Instagram é um aplicativo de rede social baseada em localização móvel que oferece aos usuários uma maneira de tirar fotos, aplicar diferentes ferramentas de manipulação (filtros) para transformar a aparência da imagem e compartilhar instantaneamente com os outros usuários e amigos no próprio aplicativo ou em outras redes sociais, como Facebook, Foursquare, Twitter, etc (HOCHMAN; SCHWARTZ, 2012).

Segundo Azambuja (2012), as novas mídias possibilitam uma reapropriação comunicativa da cultura e da cultura comunicativa, já que elas diversificam e intensificam a comunicação e, sobretudo, a transformam em sentido profundo, considerando que o poder de produção e de comunicação são transferidos para os cidadãos comuns. Isso significa dizer que a comunicação passa de excludente (de poucos para muitos) para um tipo de comunicação interativa (de muitos para poucos).

Keen (2012, p. 10), por sua vez, define a mídia social como um lugar, uma "zona permanente de autoexposição de nossa nova era digital" onde podemos, por meio dos 
dispositivos eletrônicos (como smartphones, tablets, etc), publicar coletivamente o retrato de grupo em movimento do mundo. Para o autor, o que antes era chamada de vida virtual ou segunda vida, está se tornando de fato a própria vida por causa da mídia social. Diante disso, “a mídia social é como estar em casa; é a arquitetura em que habitamos" (KEEN, 2012, p.10).

O Instagram integra esse cenário das novas mídias e, para Carrera (2012, p.160), pode ser visto como "um elemento atuante em uma rede de relações em constante mudança, sendo, assim como os sujeitos, fundamental para a modificação do curso social”.

Mas o que faz o Instagram diferente de outras redes sociais? Para Linaschke (2011), o que muda é o foco. O Instagram é único, pois é inteiramente sobre a fotografia. Quando acessamos o Instagram, podemos ver alguns textos e comentários, mas o foco é realmente a fotografia, diferente de outras do Facebook ou do Twitter, por exemplo.

Segundo Silva (2012), o Instagram consolida a demanda de visibilidade do sujeito contemporâneo, altera o modelo convencional de se fotografar na era digital. É importante dizer que, nas redes sociais, o papel dos observadores (plateia) para sucesso da representação é essencial, uma vez que é por meio deles que há a legitimação da imagem construída. Sem a participação do interlocutor, a identidade e os papéis representados não adquirem a validade necessária à interação (CARRERA, 2012). Uma prova disso é o mercado de seguidores e likes para o Instagram. Possuir seguidores e curtidas no Instagram é tão importante que as pessoas chegam a comprar seguidores e curtidas em sites especializados, e muitas outras dispostas a trocar com outras pessoas totalmente desconhecidas likes, comentários, etc.

Na visão de Gomes (2012), no processo de midiatização da sociedade, as imagens ganham cada vez mais espaço na vida dos indivíduos, constituindo os imaginários e operando como vetores de sentido. Para ele, o mundo midiatizado parece estar se (re)descobrindo no que diz respeito as imagens, fato que pode ser provado pela avalanche de fotografias, ilustrações, animações, vídeos etc. que nos alcança diariamente. Ainda segundo o autor, essa abundância de vídeos e fotografias que se encontra em toda parte, trata-se de uma reconfiguração da forma como nos comunicamos, que afeta também as práticas sociais e de sentido.

Para Loizos (2012), o visual e a mídia exercem importantes funções na vida social, política e econômica. Para o autor, eles se tornaram fatos sociais e por este motivo não podem ser ignorados. A imagem, oferece um registro restrito, porém poderoso das ações temporais e dos acontecimentos reais (LOIZOS, 2012). Ferro (2005) nos diz que o visual é de grande importância no processo de conhecimento da realidade social, por isso, o uso da fotografia 
como técnica de recolha de dados na pesquisa sociológica é de grande relevância (FERRO, 2005).

\section{MÉTODOS}

Esta é uma pesquisa de característica quali-quantitativa e que utiliza o método netnográfico para a coleta de dados. Netnografia, segundo Fragoso, Recuero e Amaral (2013) é um neologismo criado nos anos 90, a partir dos termos net + etnografia, com o objetivo de demarcar as adaptações do método etnográfico em relação à coleta e a análise de dados, além da ética em pesquisa.

Para alcançar os objetivos da pesquisa, foi criado um check-list para a análise de imagens, que permite uma categorização das fotografias postadas com relação ao tipo, local, momento em que foram tiradas e informações como uso de hashtags, apelo aos patrocinadores, destaque ao corpo ou as vestimentas dos atletas.

Esta pesquisa baseia-se na Sociologia Visual, que trata de um campo disciplinar no qual a imagem é fonte de dados para a investigação (FERRO, 2005)

Foram selecionados para as análises os perfis no Instagram de atletas brasileiros medalhistas dos Jogos Olímpicos de Londres, realizado no ano de 2012. De acordo com informações presentes no site Portal Brasil (2012), 136 homens e 123 mulheres participaram dos Jogos Olímpicos de 2012, totalizando 259 atletas na delegação brasileira. O número de atletas que participaram dos Jogos Olímpicos de 2012 se tornaram medalhistas é de 58 atletas, sendo 40 do sexo masculino e 18 do sexo feminino. Porém, nem todos estes possuíam perfil no Instagram. O total de atletas que possuíam o perfil na rede social e o mantém aberto, e que, portanto, tiveram suas páginas utilizadas para esta pesquisa somam o número de 40 . Deste total, 28 são homens e 12 são mulheres, como vemos no quadro abaixo:

\begin{tabular}{|c|c|c|c|}
\hline Modalidade & $\begin{array}{c}\text { Número de Atletas com Medalha } \\
\text { e perfil no Instagram }\end{array}$ & Homens & Mulheres \\
\hline Ginástica Artística & 1 & 1 & - \\
\hline Judô & 2 & 2 & - \\
\hline Voleibol & 19 & 9 & 10 \\
\hline Boxe & 2 & 1 & 1 \\
\hline
\end{tabular}




\begin{tabular}{|c|c|c|c|}
\hline Futebol & 13 & 13 & - \\
\hline Natação & 2 & 2 & - \\
\hline Pentatlo Moderno & 1 & - & 1 \\
\hline TOTAL & $\mathbf{4 0}$ & $\mathbf{2 8}$ & $\mathbf{1 2}$ \\
\hline
\end{tabular}

Quadro 1: Apresentação do total de atletas brasileiros medalhistas olímpicos em Londres 2012 que possuem perfil no Instagram, de acordo com a modalidade e o sexo.

Fonte: elaborado pelos autores.

A coleta de dados ocorreu entre os dias 05 de janeiro e 05 de maio de 2015 . As fotos postadas antes desse período não foram analisadas. Neste período de 121 dias, foram postadas 2.025 fotos, o que totaliza uma média de 16,7 fotos publicadas por dia.

No que diz respeito à ética em pesquisa, Kozinets (2014) afirma que analisar as comunicações de comunidades ou culturas online e/ou seus arquivos não é pesquisa com seres humanos, desde que o pesquisador não registre a identidade dos comunicadores e se for possível puder obter acesso de maneira fácil e legal a essas comunicações ou arquivos. Por este motivo, foram excluídos da pesquisa os atletas cujos perfis são bloqueados, ou seja, em que é necessária uma autorização do usuário para que se possa ter acesso às suas imagens. Também optou-se pela não divulgação do nome dos atletas selecionados para essa pesquisa. Kozinets (2014) sugere ainda que, para fins de ética em pesquisa, é possível considerar o uso de alguns tipos e usos de interações culturais mediadas por computador como semelhantes à utilização de texto, e, deste modo, a análise de mensagens arquivadas não é considerada oficialmente pesquisa social com seres humanos. Sob esse ponto de vista, acreditamos que a análise de imagens postadas no Instagram por atletas que mantém seus perfis abertos também não. Por este motivo, esta pesquisa não foi submetida ao Comitê de Ética em Pesquisa.

\section{RESULTADOS E DISCUSSÃO}

Como dito anteriormente, durante a coleta de dados foram analisadas 2.025 imagens postadas pelos atletas. Deste total, 1.568 imagens são do próprio atleta ou selfies. Para estas fotos onde o atleta aparece, as análises foram mais aprofundadas.

Do número final fotos postadas, $1.348(66,5 \%)$ imagens foram postadas pelos homens, enquanto $677(33,5 \%)$ foram publicadas pelas mulheres.

Os atletas das modalidades coletivas foram responsáveis por 1.860 das fotos publicadas, o que representa aproximadamente $91 \%$ do total. Por outro lado, os atletas de 
esportes individuais publicaram apenas 165 fotos, somando 9\%. Dos atletas de equipes coletivas, os atletas de futebol (masculino) foram os responsáveis pelo maior montante de publicação, com 734 fotos. Em seguida estão as jogadoras de voleibol feminino com 665 fotos, e os atletas de voleibol masculino, somando 461 imagens.

Apresentamos abaixo a tabela com a apresentação dos atletas cujos perfis foram utilizados para esta pesquisa, assim como o sexo, modalidade a que pertencem, a medalha que conquistaram nos Jogos Olímpicos de 2012, o número de seguidores que possuíam no dia 05 de janeiro de 2015 e o total de fotos publicadas pelos atletas no período correspondente a este estudo:

\begin{tabular}{|c|c|c|c|c|c|}
\hline Atleta & Sexo & Modalidade & $\begin{array}{l}\text { Medalha nos Jogos } \\
\text { Olímpicos }\end{array}$ & $\begin{array}{c}\text { N. de Seguidores } \\
\text { em } 05 / 01 / 2015\end{array}$ & $\begin{array}{l}\text { N. de Fotos } \\
\text { Postadas }\end{array}$ \\
\hline Atleta 1 & Masculino & Ginástica Artística & Ouro & 12.411 & 12 \\
\hline Atleta 2 & Masculino & Futebol & Prata & 99.068 & 9 \\
\hline Atleta 3 & Masculino & Futebol & Prata & $3,39 \mathrm{~m}$ & 70 \\
\hline Atleta 4 & Masculino & Futebol & Prata & $3,61 \mathrm{~m}$ & 79 \\
\hline Atleta 5 & Masculino & Futebol & Prata & $1,22 \mathrm{~m}$ & 36 \\
\hline Atleta 6 & Masculino & Futebol & Prata & $2,56 \mathrm{~m}$ & 43 \\
\hline Atleta 7 & Masculino & Futebol & Prata & $112 \mathrm{k}$ & 3 \\
\hline Atleta 8 & Masculino & Futebol & Prata & $13,51 \mathrm{~m}$ & 208 \\
\hline Atleta 9 & Masculino & Futebol & Prata & $1,88 \mathrm{~m}$ & 99 \\
\hline Atleta 10 & Masculino & Futebol & Prata & 30.269 & 4 \\
\hline Atleta 11 & Masculino & Futebol & Prata & 79.097 & 71 \\
\hline Atleta 12 & Masculino & Futebol & Prata & $386 \mathrm{k}$ & 26 \\
\hline Atleta 13 & Masculino & Futebol & Prata & $1,1 \mathrm{~m}$ & 85 \\
\hline Atleta 14 & Masculino & Futebol & Prata & $20 \mathrm{k}$ & 1 \\
\hline Atleta 15 & Masculino & Natação & Prata & $12 \mathrm{k}$ & 51 \\
\hline Atleta 16 & Masculino & Vôlei & Prata & $210 \mathrm{k}$ & 77 \\
\hline Atleta 17 & Masculino & Vôlei & Prata & $41 \mathrm{k}$ & 47 \\
\hline Atleta 18 & Masculino & Vôlei & Prata & $72 \mathrm{k}$ & 126 \\
\hline Atleta 19 & Masculino & Vôlei & Prata & 6.460 & 0 \\
\hline Atleta 20 & Masculino & Vôlei & Prata & 9.537 & 22 \\
\hline Atleta 21 & Masculino & Vôlei & Prata & $44 \mathrm{k}$ & 62 \\
\hline Atleta 22 & Masculino & Vôlei & Prata & $25 \mathrm{k}$ & 22 \\
\hline Atleta 23 & Masculino & Vôlei & Prata & $12 \mathrm{k}$ & 41 \\
\hline Atleta 24 & Masculino & Vôlei & Prata & $36 \mathrm{k}$ & 64 \\
\hline Atleta 25 & Masculino & Boxe & Bronze & 1.633 & 26 \\
\hline Atleta 26 & Masculino & Judô & Bronze & 2.089 & 23 \\
\hline Atleta 27 & Masculino & Judô & Bronze & 4.392 & 31 \\
\hline Atleta 28 & Masculino & Natação & Bronze & $11 \mathrm{k}$ & 10 \\
\hline Atleta 29 & Feminino & Vôlei & Ouro & 46.335 & 147 \\
\hline
\end{tabular}




\begin{tabular}{|c|c|c|c|c|c|} 
Atleta 30 & Feminino & Vôlei & Ouro & 42.119 & 19 \\
\hline Atleta 31 & Feminino & Vôlei & Ouro & 5.271 & 12 \\
\hline Atleta 32 & Feminino & Vôlei & Ouro & 35.735 & 134 \\
\hline Atleta 33 & Feminino & Vôlei & Ouro & $108 \mathrm{k}$ & 100 \\
\hline Atleta 34 & Feminino & Vôlei & Ouro & 3.069 & 32 \\
\hline Atleta 35 & Feminino & Vôlei & Ouro & 19.038 & 63 \\
\hline Atleta 36 & Feminino & Vôlei & Ouro & $102 \mathrm{k}$ & 88 \\
\hline Atleta 37 & Feminino & Vôlei & Ouro & 31.471 & 29 \\
\hline Atleta 38 & Feminino & Vôlei & Ouro & 18 & 0 \\
\hline Atleta 39 & Feminino & Boxe & Prata & 1.189 & 12 \\
\hline Atleta 40 & Feminino & Pentatlo Moderno & Bronze & \\
\hline
\end{tabular}

Quadro 2: Apresentação detalhada dos atletas brasileiros cujos perfis no Instagram foram utilizados na coleta de dados para esta pesquisa.

Fonte: elaborado pelos autores

Os dados apresentados sobre o número de seguidores no Instagram aparecem neste quadro exatamente como é oferecido pela própria rede social em questão. A letra K representa o número mil e a letra $\mathrm{M}$, o número de milhão/milhões de seguidores. Ou seja, onde vemos o número $11 \mathrm{k}$, significa que o atleta possui 11 mil seguidores, e onde se vê o 3,39m, entende-se que o atleta possui 3,39 milhões de pessoas que o seguem.

É interessante ressaltar que os 10 atletas que possuem o maior número de seguidores são homens. A mulher com o maior número de seguidores é a Atleta 33, com 108 mil seguidores, que ocuparia o décimo primeiro lugar em uma lista dos atletas mais seguidos no Instagram. Este fato reforça que a hegemonia do esporte masculino frente ao feminino também continua na rede social.

Além dos jogadores de futebol serem os que mais postaram imagens no período da pesquisa, são também os mais seguidos no Instagram. Esta informação nos causa interesse, mas não espanto. Já é sabido que os futebolistas, especificamente os homens, são verdadeiras celebridades. Em um levantamento rápido realizado no dia 08 de janeiro de 2016 no Instagram, constatamos que Cristiano Ronaldo, jogador do Real Madrid F. C. e da Seleção Portuguesa de Futebol possui 43,6 milhões de seguidores. Messi, atleta do F. C. Barcelona e da Seleção Argentina, possui 33,1 milhões de fãs na rede social. São números grandiosos, principalmente quando comparamos com outras grandes celebridades mundiais. Barack Obama possui 5.7 milhões de seguidores no Instagram. A top model brasileira e internacionalmente conhecida Gisele Bündchen, possui 7.4 milhões.

Notamos que os resultados sugerem uma relação entre a quantidade de seguidores e o total de fotos que o atleta publica. Um dos atletas da pesquisa, nomeado como "Atleta 8" 
pertence a modalidade futebol e é do sexo masculino. Este é o atleta participante da pesquisa que mais possui seguidores e também o que mais fotos publicou. Em 5 de janeiro de 2015 o Atleta 8 possuía mais de 13 milhões de seguidores, e postou em um período de quatro meses 208 fotografias no Instagram, o que gera uma média de 1,7 fotos por dia.

Diante disso, vemos que a exposição nas redes sociais é constante. Publicar no Instagram parece ser parte da rotina destes atletas. Para Martins (2013), a cultura popular da imagem considera lícita a transformação de certos momentos da vida e certas situações em imagem fotográfica, porém considera que alguns momentos e situações não podem ser invadidos por fotógrafos e bisbilhoteiros em geral. Isso explica porque compartilhar imagens torna-se uma forma legítima de comunicação com o mundo. Para Ferreira (2013) é possível perceber que cada vez mais deixa-se de lado a privacidade por um ganho simbólico de popularidade e fama. Para o autor, há um espetáculo em torno do indivíduo, que além de consumir, também produz material, e esse é cada vez mais focado em si próprio.

Ainda sobre o valor e poder simbólico, instituições como a família, a escola, a religião e também a mídia seriam sistemas integrado de padrões de comportamento e representações. Toda a forma de comunicação, assim como os discursos, as mensagens, etc. são também signos de autoridade, que devem ser obedecidos (BOURDIEU, 1989). Neste modo de entender os fenômenos da sociedade, acreditamos que as redes sociais também servem como um meio para a disseminação de símbolos e signos que devem ser seguidos. No caso dos esportistas que se mostram na rede social, valores como sucesso, fama, superação, bem estar financeiro, vitórias e etc. estão associados a imagem que é passada por meio de suas publicações.

Bourdieu (1989) nos traz também o conceito de campo, que seria o espaço de relações entre grupos diferentes, ou ainda o espaço de disputa de poder. Para o autor, a sociedade é composta de vários campos, que possuem regras próprias e uma autonomia relativa. As redes sociais, neste contexto, são mais um campo onde esta dinâmica citada também acontece de forma clara.

Para Bourdieu (1983), quando a prática esportiva é associada ao consumo, o chamado esporte espetáculo torna-se claramente uma mercadoria de massa, enquanto os espetáculos esportivos configuram-se em um ramo do show business. Para o autor, as práticas e os consumos esportivos mudaram ao longo dos anos, e o princípio destas mudanças está na relação entre as transformações da oferta (invenção ou importação de novos esportes, novos equipamentos ou produtos, etc) e as transformação da demanda (ou seja, dos estilos de vida, e 
que por isso obedecem às leis gerais desta transformação). Neste cenário, a nova dinâmica imposta pelas redes sociais permite que tanto a demanda quanto a oferta sejam alteradas de forma significativa, propiciando infinitas novas possibilidades em um universo baseado no consumo.

\subsection{Tipos de Fotos}

As análises de acordo com o check-list criado começam pelos tipos de foto que são postadas pelos atletas no Instagram. Das 2.025 fotos publicadas no período da pesquisa, 994 imagens $(49,1 \%)$ são do próprio atleta. Em seguida, aparece a categoria "Montagens", com 284 ocorrências (14,0\%). Em terceiro lugar, com 12,8\%, aparecem as selfies com outras pessoas além do atleta. Logo após aparecem as selfies onde aparece apenas o atleta com 154 (7,6\%) ocorrências. Em seguida estão as imagens de terceiros (4,2\%) os memes $(2,7 \%)$, as imagens de objetos $(2,4 \%)$, de paisagens $(1,5 \%)$ e, por último, de comidas e pets, empatadas com 1,1\%. Em 70 casos (3,5\%), as fotos foram enquadradas na categoria "Outros". Abaixo podemos visualizar o gráfico que apresenta estes dados.

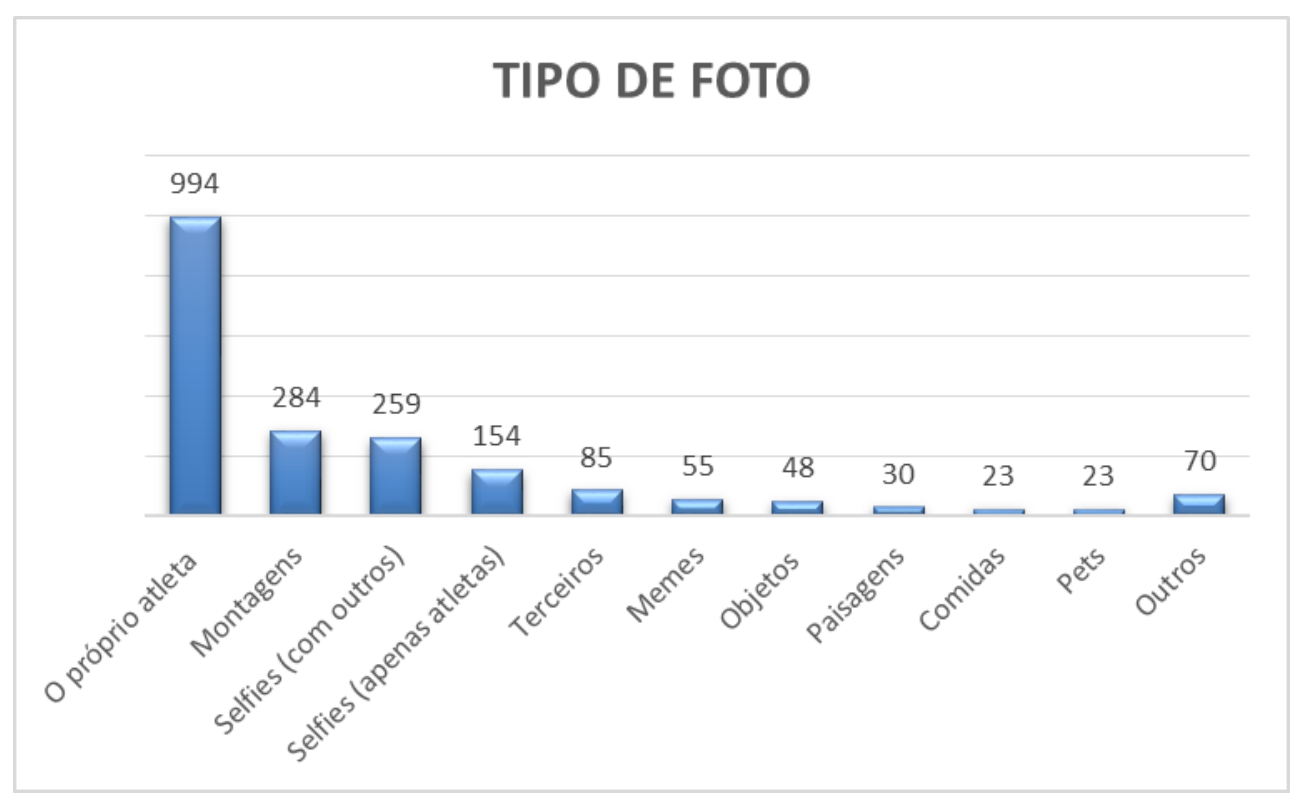

Gráfico 1: Total em números absolutos do tipo de fotos postadas pelos atletas desta pesquisa. Fonte: elaborado pelos autores.

Este fato vai de encontro aos achados de Bakhshi, Shamma e Gilbert (2014), que afirmam que um dos tipos mais comuns de conteúdo de fotos compartilhadas nas mídias sociais são fotos de pessoas ou com faces humanas. Os autores nos mostram que as imagens com rostos são $38 \%$ mais propensas a receber curtidas (likes), possuem $32 \%$ mais 
probabilidade de receber comentários, e que o número de rostos presentes na imagem, idade e sexo dos que ali estão não causam efeito sobre esses números (BAKHSHI; SHAMMA; GILBERT, 2014).

\subsection{Local das Fotos}

Em 1.568 do total de fotos postadas os atletas pesquisados estavam presentes. Para estas imagens, continuamos as análises, iniciando pelo local onde as fotos foram realizadas. A maior parte das fotos, ou seja, 37,5\% delas foram feitas nos centros de treinamentos, estádios, ginásios, vestiários e outros locais diretamente ligados à atividade profissional do atleta e ao esporte. Em seguida aparecem as categorias "Locais de Lazer" com 14,9\% das fotos postadas, "Casa" com 9,9\%, "Meios de Transporte" com 4,7\% e "Academia" com 1,8\%. A categoria “Não Foi Possível Definir" obteve um número considerável de ocorrências, com 19,3\% das fotos publicadas. Isso acontece pois em algumas imagens é difícil dizer com exatidão onde a foto foi realizada, como por exemplo, quando uma selfie é tirada com a câmera muito próxima ao rosto do atleta e não é possível ver o entorno. Ou ainda, quando as condições de luminosidade ou nitidez da foto não são as ideais. Para finalizar, 11,9\% das imagens foram realizadas em outros locais, que não se encaixam nas outras categorias presentes no instrumento criado para a realização deste trabalho, como podemos observar no gráfico abaixo.

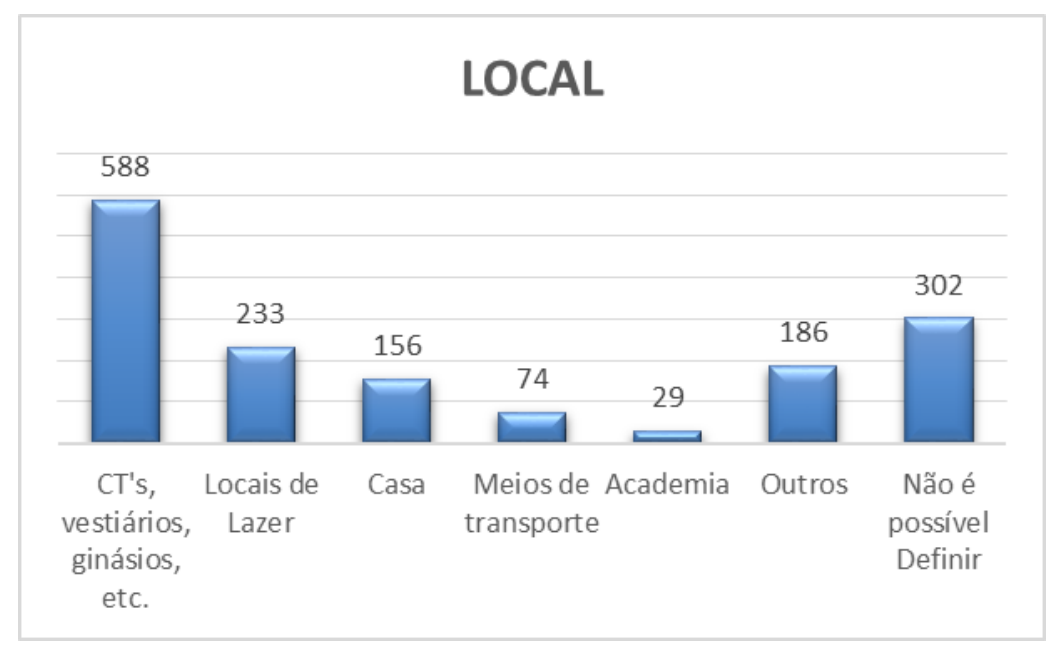

Gráfico 2: Total em números absolutos do local onde foram feitas as fotos postadas pelos atletas desta pesquisa Fonte: elaborado pelos autores. 


\subsection{Momento das Fotos}

Para o momento que as fotos foram feitas, vale ressaltar que mais da metade $(51,5 \%)$ das imagens postadas no período analisado sugerem que foram fotografadas em momentos de descontração. Em seguida estão as fotos feitas em momentos de trabalho, com 23,6\% do total de fotos. Logo após temos as fotos em momentos de lazer (14,9\%) e de descanso (2,7\%). Em 7,3\% das imagens não foi possível definir em qual momento foram feitas. Abaixo podemos ver o gráfico em que são representados estes números.

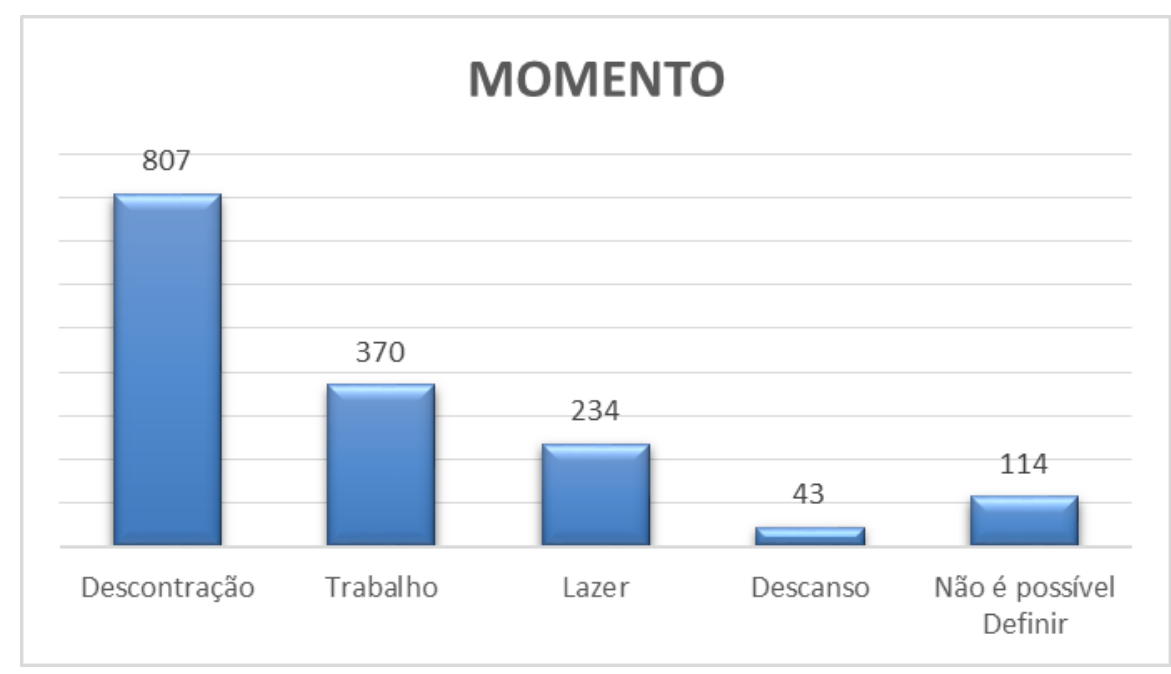

Gráfico 3: Total em números absolutos do momento em que foram realizadas as fotos postadas pelos atletas desta pesquisa

Fonte: elaborado pelos autores.

\subsection{Presença de Hashtags, Patrocinadores, Destaque ao Corpo e à Vestimenta Nas Fotos}

No que diz respeito aos patrocinadores, a maioria das fotos, $61,2 \%$ das imagens não possui referências aos patrocinadores dos atletas, o que faz com que 38,8\% das fotos postadas contenham alguma forma de propaganda. Descobrimos também que em 54,2\% das postagens os atletas optaram por usar as hashtags. Já em 45,8\%, as hashtags não aparecem.

Em relação ao destaque ao corpo, encontramos que na maior parte das fotos $(94,2 \%)$ ele não é dado, apontando que em apenas $5,8 \%$ das postagens aparece algum destaque ao corpo dos atletas. O mesmo acontece com o destaque à vestimenta, já que em 94,3\% das postagens esse apelo à roupa que atleta utiliza não é percebido, contra 5,7\% das imagens onde esse destaque é dado, como vemos nos gráficos abaixo. 


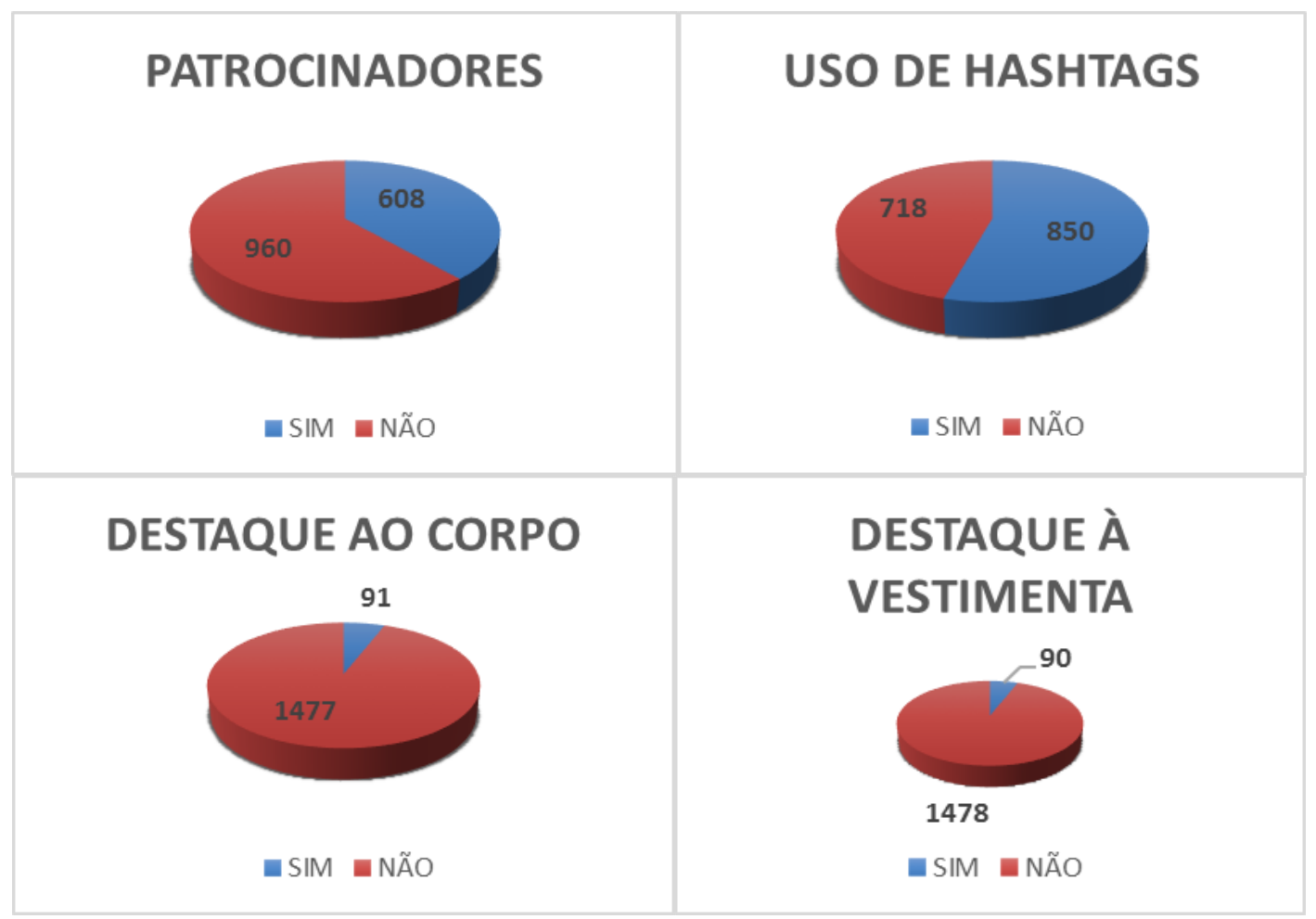

Gráficos 4, 5, 6 e 7: Total em números absolutos da existência de referência aos patrocinadores, presença de hashtags, do destaque ao corpo e à vestimenta, respectivamente, nas fotos postadas pelos atletas desta pesquisa. Fonte: elaborado pelos autores.

Apesar do potencial das redes sociais para a promoção de marcas, o número de fotos com propagandas de patrocinadores parece ser pequeno. $\mathrm{O}$ destaque ao corpo e à vestimenta também é pouco aparente e explorado. Já o uso de hashtags na maioria das fotos indica uma tentativa de tornar a foto popular, pois a foto que as contém, possui uma maior possibilidade de ser encontrada e visualizada nas redes sociais.

\section{CONSIDERAÇÕES FINAIS}

O presente trabalho esclarece uma nova tendência e necessidade da vida contemporânea, que é mostrar-se nas redes sociais. Com os esportistas, isso não é diferente. Os dados desta pesquisa revelam que os atletas estão presentes na maioria das imagens postadas. Nesta linha de pensamento, o Instagram acumula duas funções: a de criar novas celebridades e de reafirmar a fama daqueles que já a possuem.

Por outro lado, as fotos publicadas pelos atletas possuem um ar descompromissado, já que a maior parte das fotos são postadas em momentos de descontração. Mas não podemos esquecer que o local onde a maior parte das fotos foram realizadas foram em locais 
relacionados ao trabalho dos atletas (centros de treinamentos, vestiários, ginásios, estádios, etc.), o que pode indicar uma tentativa de afirmar a identidade esportiva destes usuários, ou seja, reforçar a imagem do atleta como atleta. Além disso, o uso frequente de hashtags indica que os indivíduos desta pesquisa pretendem aumentar o número de visualizações das suas imagens.

Não podemos deixar de notar também que algumas fotos são claramente formas de promoção para os próprios atletas e para os seus patrocinadores. Apesar do pequeno número de fotos onde estão presentes o destaque ao corpo, às vestimentas dos atletas e aos seus patrocinadores, algumas imagens são claramente uma forma de propaganda. Isso deve ser levado em conta, pois está relacionado com retornos financeiros aos atletas.

Por outro lado, não podemos esquecer da presença dos profissionais do media training no universo esportivo, responsáveis por treinar e cuidar dos perfis dos atletas nas redes sociais. Neste cenário, torna-se mais complexo tentar entender o quanto o atleta é realmente responsável pela publicação, o quanto isso é espontâneo. Além disso, é preciso lembrar também que nem tudo que vemos na rede é, de fato, verdade, independente de quem seja o usuário. Porém, partindo das definições entre real e virtual, precisamos considerar que o virtual também é real, passando a ser uma verdade. Se a imagem postada está lá, independente de representar um fato como ele realmente aconteceu ou não, ela possui significados a serem considerados.

Ao final de tudo isso, tentamos responder a principal questão desta pesquisa: o que os atletas costumam publicar em seus perfis do Instagram? A resposta mais clara para esta questão parece ser: os atletas publicam-se no Instagram. A maior parte das postagens feitas são centradas nos atletas, onde são eles o ponto central das publicações. Além disso, parece haver uma necessidade de mostrarem-se como atletas, enfatizando suas profissões. É uma forma de promoção pessoal, embora o marketing propriamente dito seja pouco explorado nas redes sociais, fato que pode ser comprovado pelo baixo número de fotos onde aparecem alguns dos patrocinadores dos atletas.

Ao final deste trabalho, pensamos em outras possibilidades para estudos futuros, dentre elas: explorar as hashtags e as legendas (o conteúdo textual das publicações); estudar o número de curtidas de cada foto postada; comparar atletas de diferentes modalidades, em diferentes países e/ou realidades. Além disso, após este trabalho descritivo, existe a possibilidade de uma análise estatística mais aprofundada, explorando correlações. 
Acreditamos que em um mundo cada vez mais social e conectado, é importante dar continuidade aos estudos nessa área.

\section{REFERÊNCIAS}

AZAMBUJA, C. C. Efeitos McLuhan. In: MONTAÑO, S.; FISCHER, G.; KILPP, S. (Orgs). Impacto das novas mídias no estatuto de imagem. Porto Alegre: Sulina, 2012, p. 87-94.

BAKHSHI, S. SHAMMA, D. A. GILBERT, E. Faces Engage Us: photos with faces attract more likes and comments on Instagram. In: SIGCHI Conference, 2014, Toronto.

Proceedings... Toronto: SIGCHI, 2014. p. 965-974.

BOURDIEU, P. Como é possível ser esportivo? In.: BOURDIEU, P. Questões de sociologia. Rio de Janeiro: Marco Zero, 1983. p 136-153.

BOURDIEU, P. O poder simbólico. Lisboa/Rio de Janeiro: Bertrand Brasil/Difel, 1989. Disponível em:

<http://lpeqi.quimica.ufg.br/up/426/o/BOURDIEU_Pierre._O_poder_simb\%C3\%B3lico.pdf $>$. Acesso em: 21 set. 2017.

CARRERA, F. Instagram no Facebook: uma reflexão sobre ethos, consumo e construção de subjetividade em sites de redes sociais. Revista Interamericana de Comunicação Midiática, v. 12, n. 22, p. 148-165, 2012.

FERREIRA, S. S. A nostalgia da imagem: o Instagram como tendência contemporânea. 2013. 24f. Monografia (Pós-graduação em Mídia, Informação e Cultura) - Escola de Comunicação e Artes, Universidade de São Paulo, São Paulo, 2013.

FERRO, L. Ao Encontro da Sociologia Visual. Revista da Faculdade de Letras da Universidade do Porto, n.15, p. 373-398, 2005.

FRAGOSO, S.; RECUERO, R.; AMARAL, A. Métodos de pesquisa para internet. Porto Alegre: Sulina, 2013.

GOMES, M. S. Imagens midiatizadas: comunicando a si mesmas. In: MONTAÑO, S.; FISCHER, G.; KILPP, S. (Orgs). Impacto das novas mídias no estatuto de imagem. Porto Alegre: Sulina, 2012. p. 197-203.

HOCHMAN, N.; SCHWARTZ, R. Visualizing Instagram: tracing cultural visual rhythms. In: INTERNACIONAL AAAI CONFERENCE ON WEBLOGS AND SOCIAL MEDIA, 6 , 2012, Dublin. Proceedings... Menlo Park: AAAI Press, 2012. p. 6-9.

KEEN, A. Vertigem digital: por que as redes sociais estão nos dividindo, diminuindo e desorientando? Rio de Janeiro: Zahar, 2012.

KOZINETS, R. V. Netnografia: realizando pesquisa etnográfica online. São Paulo: Penso Editora, 2014. 
LEMOS, A. Cultura da Mobilidade. FAMECOS, n. 40, dez. 2009.

LÉVY, P. Cibercultura. São Paulo: Editora 34, 1999.

LINASCHKE, J. Getting the most from Instagram. Berkeley: Peachpit Press, 2011.

LOIZOS, P. Vídeo, filme e fotografias como documento de pesquisa. In: BAUER, M. W.; GASKELL, G. (Orgs.). Pesquisa qualitativa com texto, imagem e som: um manual prático. Petrópolis: Vozes, 2012. p.137-155.

MARTINS, J. S. Sociologia da Fotografia e da Imagem. 2 ed. São Paulo: Editora Contexto, 2013.

PIZA, M. V. O fenômeno Instagram: considerações sob a perspectiva tecnológica. 2012. 48f. Monografia (Bacharel em Ciência Sociais) - Departamento de Sociologia, Universidade de Brasília, Brasília, 2012.

\section{PORTAL BRASIL. Delegação brasileira terá 259 atletas nos Jogos Olímpicos}

Londres 2012. 2012. Disponível em

<http://www.brasil.gov.br/esporte/2012/07/delegacao-brasileira-tera-259-atletas-nosjogosolimpicos-londres-2012>. Acesso em: 08 jan. 2016.

SILVA, P. I. R. Instagram: um modo de narrar sobre si, fotografar ou de olhar para se ver. In: CONGRESSO DE CIÊNCIAS DA COMUNICAÇÃO NA REGIÃO SUDESTE, 17, 2012, Ouro Preto. Anais... Ouro Preto: 2012.

Original recebido em: 25 de julho de 2016

Aceito para publicação em: 19 de setembro de 2017

Vivian de Oliveira

Docente no curso de Educação Física do Centro Universitário FIEO (Osasco, Brasil). Bacharela em Educação Física pelo Instituto de Biociências da Universidade Estadual Paulista "Júlio de Mesquita Filho" (UNESP), campus de Rio Claro. Realizou intercâmbio acadêmico na Faculdade de Motricidade Humana (Universidade de Lisboa) em Lisboa, Portugal, cursando Ciências do Desporto. Mestra em Desenvolvimento Humano e Tecnologias (UNESP-Rio Claro). Membra do Laboratório de Estudos e Pesquisa em Psicologia do Esporte (LEPESPE) desde 2010.

André Luis Aroni

Possui Licenciatura Plena em Educação Física pela PUC (2002), Especialização em Fisiologia do Exercício pela UVA (2005), Especialização em Atividade Motora Adaptada pela UNICAMP (2006), Mestrado em Treino Desportivo pela ULHT de Lisboa - Portugal (2011), Doutorado no programa de Desenvolvimento Humano e Tecnologias da UNESP, com bolsa CAPES no país e PDSE na Florida State University - Estados Unidos. Pesquisador do Laboratório de Estudos e Pesquisas em Psicologia do Esporte (UNESP) e pesquisador associado do Sport Psychology Organization \& Research Team

(Florida State University). Docente dos cursos de graduação em Educação Física, Fisioterapia e Nutrição da DeVry/Metrocamp (Campinas/SP). Docente convidado nos cursos de Pós-graduação em

Psicologia do Esporte do Grupo Educacional Estácio e Centro Universitário FACEX (Natal/RN). 
Parecerista na Revista Cientefico - DeVry Brasil (ISSN: 1677-1591). Tem experiência na área de Educação Física com ênfase em Psicologia do Esporte e Golfe, atuando principalmente nos seguintes temas: pico de performance, auto-determinação e estresse competitivo.

Luciana Botelho Ribeiro

Doutoranda e mestre em Desenvolvimento Humano e Tecnologias pela (UNESP - Rio Claro).

Licenciada em Educação Física pela Universidade Federal de Lavras (UFLA) e bacharel em Fisioterapia pelo Centro Universitário de Lavras (UNILAVRAS). Tutora do curso de graduação em Pedagogia da Universidade Federal de Lavras (UFLA) nas disciplinas: Seminário de Pesquisa em Educação VII e VIII e Saúde, alimentação e nutrição I e II. Tutora do curso de pós-graduação em Educação Física da Universidade Integrada AVM (Brasília) nas disciplinas: Motivação no Esporte e na Atividade Física; Liderança e Processos Grupais e Preparação Psicológica do atleta de alto rendimento.Membro dos Grupos de pesquisas LEPESPE (Laboratório de Estudos e Pesquisas em Psicologia do Esporte- UNESP) e do LAPPEX (Laboratório de Pesquisa em Psicologia do Exercício-

UFLA).

\section{Kauan Galvão Morão}

Bacharel em Educação Física pela Universidade Estadual Paulista Júlio de Mesquita Filho (2012). Licenciado em Educação Física pela mesma universidade citada anteriormente (2014). Mestrando no Programa de Pós Graduação em Desenvolvimento Humano e Tecnologias na UNESP, campus de Rio

Claro. Membro do Laboratório de Estudos e Pesquisas em Psicologia do Esporte (LEPESPE), desde 2009 , realizando estudos, pesquisas e trabalhos junto a um grupo de jovens pesquisadores que abordam diversas áreas dentro da psicologia esportiva.

Afonso Antonio Machado

Licenciado em Educação Física pela PUC- Campinas (1976); graduado em Filosofia e Pedagogia. Mestre (1985) e doutor (1994) em Educação, pela UNICAMP. Livre-docente pelo Instituto de

Biociências, UNESP, Rio Claro, com a tese \&quot;Agressividade e ansiedade em atletas jovens\&quot;(1998). Editor-chefe da Revista MOTRIZ, membro editorial da Revista Brasileira de Educação Física, Esporte, Lazer e Dança (REFELD), da Revista Iberoamericana de Psicología del Ejercício e del Deporto, da Revista Movimento, da Revista Movimento\&Percepção e da Coleção Pesquisa em Educação Física. Professor adjunto na UNESP/ Rio Claro, em RDIDP. Atua na Educação

Física, com ênfase nos temas: estados emocionais, identidade psicológica do esportista, gênero e masculinidade no esporte e lesões psicológicas esportivas. Coordena o LEPESPE (Laboratório de Estudos e Pesquisas em Psicologia do Esporte), foi presidente da SOBRAPE (Sociedade Brasileira de

Psicologia do Esporte, de 2006-08). Realizou estágio de pós-doutoramento no Laboratório de

Psicologia do Esporte, junto ao Prof. Dr. Duarte Araújo, da Faculdade de Motricidade Humana, em Lisboa(08-09) e na Universidade do Minho, com Prof. Dr. António Rui Gomes (10-11). Bolsista PQ (2010-13). Coordenador do Programa de Pós-graduação em Desenvolvimento Humano e Tecnologias

(DEHUTE), no IB/UNESP. 